\title{
Psycho-Oncology
}

Journal of the Psychological, Social and

Behavioral Dimensions of Cancer

\section{Identifying the Key Characteristics of Clinical Fear of Cancer Recurrence: An International Delphi Study}

\begin{tabular}{|r|l|}
\hline Journal: & Psycho-Oncology \\
\hline Manuscript ID & PON-19-0478.R1 \\
\hline Wiley - Manuscript type: & Paper \\
\hline Author: & $29-$ Oct-2019 \\
\hline Complete List of Authors: & $\begin{array}{l}\text { Mutsaers, Brittany; University of Ottawa, School of Psychology } \\
\text { Butow, Phyllis; The University of Sydney, Centre for Medical Psychology } \\
\text { \& Evidence-based Decision-making } \\
\text { Dinkel, Andreas; Klinikum rechts der Isar, Technical University of } \\
\text { Munich, Department of Psychosomatic Medicine and Psychotherapy; } \\
\text { Humphris, Gerry; University of St Andrews, } \\
\text { Maheu, Christine; McGill University, Ingram School of Nursing } \\
\text { Ozakinci, Gozde; University of St Andrews, Health Psychology, School of } \\
\text { Medicine } \\
\text { Prins, Judith; Radboud university medical center, Department of Medical } \\
\text { Psychology } \\
\text { Sharpe, Louise; The University of Sydney, Clinical Psychology Unit } \\
\text { Smith, Allan Ben; Centre for Oncology Education and Research } \\
\text { Translation (CONCET), Ingham Institute for Applied Medical Research, ; } \\
\text { University of New South Wales, SWS Clinical School } \\
\text { Thewes, Belinda; University of Sydney, Centre for Medical Psychology } \\
\text { and Evidence-Based Decision-Making, School of Psychology; } \\
\text { Lebel, Sophie; University of Ottawa, Psychology }\end{array}$ \\
\hline Keywords: & $\begin{array}{l}\text { Cancer, Oncology, Definition, Expert Consensus, Delphi, Fear of Cancer } \\
\text { Recurrence }\end{array}$ \\
\hline & \\
\hline
\end{tabular}

\section{SCHOLARONE Manuscripts}


Running Head: DELPHI ON CLINICAL FCR

Identifying the Key Characteristics of Clinical Fear of Cancer Recurrence: An International Delphi Study

Brittany Mutsaers ${ }^{1 *}$, Phyllis Butow ${ }^{2}$, Andreas Dinkel $^{3}$, Gerald Humphris $^{4}$, Christine Maheu 5 , Gozde Ozakinci ${ }^{4}$, Judith Prins ${ }^{6}$, Louise Sharpe ${ }^{2}$, Allan “Ben” Smith”, Belinda Thewes² \& Sophie Lebel $^{1}$.

${ }^{1}$ University of Ottawa, Ottawa ON, Canada

2 School of Psychology, The University of Sydney, Australia

${ }^{3}$ Department of Psychosomatic Medicine and Psychotherapy, Klinikum rechts der Isar, Technical University of Munich, Germany

${ }^{4}$ School of Medicine, University of St Andrews, United Kingdom

${ }^{5}$ McGill University, Canada

${ }^{6}$ Radboud University, Netherlands

${ }^{7}$ Centre for Oncology Education \& Research Translation (CONCERT), Ingham Institute for Applied Medical Research, South Western Sydney Clinical School, UNSW, Sydney, Australia

* Corresponding author

Brittany Mutsaers

University of Ottawa

136 Jean Jacques Lussier PVT

Ottawa, ON

bmuts031@uottawa.ca 


\begin{abstract}
Objective: Without an agreed-upon set of characteristics that differentiate clinical from nonclinical levels of fear of cancer recurrence (FCR), it is difficult to ensure that FCR severity is appropriately measured, and that those in need of intervention are identified. The objective of this study was to establish expert consensus on the defining features of clinical FCR.

Method: A three-round Delphi was used to reach consensus on the defining features of clinical FCR. Sixty-five experts in FCR (researchers, psychologists, physicians, nurses, allied health professionals) were recruited to suggest and rate potential features of clinical FCR. Participants who indicated they could communicate diagnoses within their clinical role were also asked to consider the application of established DSM-5 and proposed ICD-11 diagnostic criteria (Health Anxiety, Illness Anxiety Disorder, Somatic Symptom Disorder) to clinical FCR.

Results: Participants' ratings suggested that the following 4 features are key characteristics of clinical FCR: 1) high levels of preoccupation; 2) high levels of worry; 3) that are persistent; and 4) hypervigilance to bodily symptoms. Of participants whose professional role allowed them to diagnose mental disorders $84 \%$ indicated it would be helpful to diagnose clinical FCR, but the use of established diagnostic criteria related to health anxiety or somatic-related disorders to clinical FCR was not supported. This suggests that participants consider clinical FCR as a presentation that is specific to cancer survivors.
\end{abstract}

Conclusion: Clinical FCR was conceptualized as a multi-dimensional construct. Further research is needed to empirically validate the proposed defining features.

Keywords: cancer; oncology; definition; Delphi; expert consensus; fear of cancer recurrence 
Fear of cancer recurrence (FCR) impacts most cancer survivors ${ }^{1}$ and is defined as the "the fear, worry or concern relating to the possibility that cancer will come back or progress."2, p. 3266 Given the implications of a cancer diagnosis and treatment, experiencing FCR is reasonable and expected. ${ }^{3}$ While FCR can be adaptive, ${ }^{2,3,4}$ when it is experienced at high levels of severity it leads to significant distress, decreased quality of life, ${ }^{1}$ and increased health-care use. ${ }^{5,6}$ The lack of established characteristics that differentiate normative from clinically severe FCR is a gap in FCR research, ${ }^{2,7-10}$ since these characteristics would facilitate the accurate measurement of FCR severity, the severity of FCR requiring intervention, and appropriate intervention intensity. $7,9,10$

Previous work has been conducted on identifying potential features of clinical FCR. For example, items more commonly endorsed by respondents considered to have clinical FCR on the Fear of Cancer Recurrence Inventory (FCRI) ${ }^{11}$ included: experiencing fear, worry, and anxiety; functional impairment; and frequently thinking about the negative impact that a cancer recurrence would have on one's life. ${ }^{11}$ Similarly, qualitatively analysed interviews with 40 breast, lung, colorectal, and prostate cancer survivors identified the following potential features of clinical FCR: death-related thoughts; feeling alone; belief that the cancer will return; intolerance of uncertainty; recurrent thoughts and images lasting at least 30 minutes, occur daily, are difficult to control, and cause distress; and impairment in functioning. ${ }^{12}$ The next step in FCR research is to establish consensus on the defining features of clinical FCR. ${ }^{2,7,8}$

Preliminary work on establishing consensus on the defining features of clinical FCR was conducted at an International Colloquium in 2015 at the University of Ottawa. ${ }^{2,8}$ Using one round of rating potential features of clinical FCR, 12 clinicians/clinician-researchers, 10 trainees with FCR research experience, one government funded cancer survivorship organization representative, and two patient representatives who attended the colloquium identified five 
potential features of clinical FCR. These were: 1) high levels of preoccupation, worry, rumination, or intrusive thoughts; 2) maladaptive coping (e.g., excessive reassurance seeking, avoidance); 3) functional impairment; 4) excessive distress; and 5) difficulties making plans for the future. ${ }^{2}$

To extend this work, a larger-scale Delphi study was needed to reach expert consensus on the defining features of clinical FCR. Further, consensus was needed regarding the number of features and for how long they must be present to identify clinical FCR in a cancer survivor. When considering defining features of clinical FCR, an important distinction between identifying and diagnosing clinical FCR must be made. Identifying cancer survivors with clinical FCR based on the presence of certain features for research purposes, coordinating care, providing services, etc. can be done by researchers and health care professionals, as appropriate. In contrast, communicating a diagnosis is considered a controlled act, and can only be done by specific professionals within their clinical role (e.g., in Canada, Psychology Act, 1991). ${ }^{13}$ Given the stigma associated with a diagnosis of a mental health condition and the normative response of FCR among cancer survivors, it was important to obtain expert consensus on whether clinical FCR should potentially be considered a "diagnosis." 8

When FCR is experienced at clinical levels, presenting symptoms may be similar to established diagnostic criteria for mental disorders, including anxiety disorders and hypochondriasis. ${ }^{14-15}$ Although the authors found some overlap between these disorders and FCR, ${ }^{14-15}$ newer, health-related diagnoses have been proposed that may be a better fit. The proposed diagnostic criteria for Health Anxiety (HA) in the upcoming eleventh edition of the International Classification of Diseases (ICD-11) appear to overlap with the defining characteristics of clinical FCR proposed at the FCR colloquium (Supplementary File 1). ${ }^{2,16}$ 
Based on this, consideration of established health-specific diagnostic criteria that are potentially related to clinical FCR, including ICD-11 criteria for Health Anxiety ${ }^{16}$ and the Diagnostic and Statistical Manual of Mental Disorders, Fifth Edition (DSM-5) ${ }^{17}$ criteria for Illness Anxiety Disorder (IAD) and Somatic Symptom Disorder (SSD), ${ }^{17}$ was pertinent and has not been previously proposed.

The present study was a formal Delphi on the defining features of clinical FCR that aimed to: 1) reach expert consensus on the characteristics that differentiate clinical from nonclinical FCR; 2) examine experts' views on using these features to a) identify and b) diagnose cancer survivors with clinical FCR; and 3) explore experts' views on applying already established diagnostic criteria (i.e., HA, IAD, and SSD) to clinical FCR.

\section{Method}

\section{Participants}

As the purpose of this study was to establish consensus on the defining features of clinical FCR, participants needed to have some expertise related to FCR. The inclusion criteria for expert participants were: 1) researchers (who have authored/co-authored a peer reviewed article on FCR within the last five years); 2) nurses, social workers, physicians, psychologists, or other allied health professionals (with at least five years of experience working with cancer survivors); 3) able to read and write in English; 4) access to a computer with an internet connection and; 5) willing to provide an email address to receive Rounds 2 and 3 of the Delphi study questionnaires.

Participants were recruited via email through professional organizations related to psycho-oncology and cancer survivorship, through contacting authors of recently published articles on FCR, and through snowball sampling (i.e., encouraging those who received the 
recruitment emails to forward it to colleagues who may be interested in participating). There are no clear guidelines published regarding the number of participants needed in Delphi studies, ${ }^{18}$ but the goal was to recruit a minimum of 50 participants in Round 1 in order to account for potential dropout across the three Delphi rounds. ${ }^{18}$

\section{Procedure}

Round 1. Qualtrics survey software was used to distribute and collect the data from the Delphi rounds. A link to the first of three Delphi rounds was included in the recruitment email. The Round 1 questionnaire contained a brief socio-demographic and eligibility-screening questionnaire. Those who did not meet the inclusion criteria did not complete the subsequent questionnaires. Participants were then presented with the suggested characteristics of clinical FCR from the International Colloquium on FCR and were asked to rate the extent to which they thought each item was characteristic of clinical FCR using a 10-point rating scale where 0 indicated the item "is not a characteristic of clinical FCR" and 10 indicated the item "is a characteristic of clinical FCR." In this round, participants also had the opportunity to list up to five additional characteristics of clinical FCR and up to five additional maladaptive coping strategies associated with clinical FCR. From a methodological standpoint, presenting previously suggested items of clinical FCR focused the additional suggestions, which streamlined the analysis by making the volume of suggestions more manageable. ${ }^{18}$

Participants were also asked to consider whether the item "difficulty making plans for the future" from the results of the Delphi conducted at the International Colloquium on FCR should be considered a standalone feature of clinical FCR or an aspect of functional impairment. This question was included because impairment in functioning could encompass difficulties making plans for the future. ${ }^{2}$ 
Consensus. There are multiple ways in which consensus can be defined for Delphi studies, and thus it is recommended that a consensus rating be established before the start of the Delphi rounds. ${ }^{18}$ For the present study, a characteristic of clinical FCR was considered to have reached consensus when at least $70 \%$ of participants rated the item $8 / 10$ or higher. Using a high cut-off of eight on a ten point rating scale was chosen to avoid obtaining features that could apply to cancer survivors who are not experiencing clinically significant levels of FCR. A consensus level of $70 \%$ of participants rating the item $8 / 10$ or higher for specific features of clinical FCR to be retained was chosen to be both conservative, and to ensure that consensus would be reached (i.e., a consensus level of $100 \%$ is not feasible). ${ }^{19}$

The results from Round 1 were summarized by calculating the percent of participants who rated each item $8 / 10$ or higher. For the Yes/No and fixed response option questions, the percentage of participants choosing each response option was calculated. Content analysis was used to summarize participants' responses to open-ended questions. Similar statements across participants were grouped together and a summary statement for each group was assigned to represent the overall meaning of the responses. ${ }^{18,20}$ The content analysis was conducted by hand by the first author and checked by the last author. Data collection for Round 1 occurred from February 1, 2018 to March 30, 2018.

Round 2. The items from Round 1 that reached consensus were presented to participants along with the content analysed suggestions of additional potential features of clinical FCR from Round 1. In Round 2, participants were asked to rate these additional potential features of clinical FCR as in Round 1, using the same 10-point rating scales.

The results of Round 2 were analyzed by calculating the percentage of participants rating each item 8/10 or higher. The data were collected for Round 2 from April 30 to May 21, 2018. 
Round 3. The final Delphi round consisted of three sections focused on: 1) identifying individuals with clinical FCR; 2) diagnosing individuals with clinical FCR; and 3) applying previously established diagnostic criteria to clinical FCR.

Specifically, participants were asked to indicate whether they believed that it would be useful to identify individuals with clinical FCR. Those who responded 'Yes' were presented with the items that reached consensus from the first two Delphi rounds. Participants were then asked to indicate which of the characteristics, how many characteristics, and the duration that these characteristics need to be present to warrant the identification of clinical FCR in a cancer survivor.

Participants were then asked to indicate whether they could communicate a diagnosis in their profession.* Only those who answered yes completed the remainder of Round 3. These participants were then asked to indicate whether they thought it would be helpful to diagnose clinical FCR. Those who responded 'Yes' were presented with the items that reached consensus in the previous two rounds. Participants were then asked to indicate which of these features, how many, and the duration required to warrant a diagnosis of clinical FCR. Descriptive statistics were calculated (mean, median, range) for the number of characteristics and the duration of time each characteristic must be present in order to identify and/or diagnose an individual with clinical FCR.

The final section of Round 3 asked participants to consider the applicability of the upcoming ICD-11 criteria for Health Anxiety, and the DSM-5 criteria for IAD and SSD to clinical FCR. The diagnostic criteria for these three disorders were presented to participants, who

\footnotetext{
${ }^{*}$ The controlled act of communicating a diagnosis is only applicable to specific professions. ${ }^{13}$ When considering a hypothetical diagnosis of clinical FCR only those who could diagnose within their professional role were included in this section.
} 
were then asked to indicate whether or not they would feel comfortable using these diagnostic criteria to diagnose an individual with clinical FCR. The percentage of participants responding 'Yes' was calculated for these questions (Supplementary Figure 1, Supplementary files 1 and 2).

\section{Ethical Approval}

Ethical approval was provided by the University of Ottawa Research Ethics Board (H08-17-45). The consent form was presented first upon clicking the Round 1 questionnaire link. Participants provided consent by clicking "I consent."

\section{Results}

\section{Participants}

Sixty-five experts participated in the first Delphi round. The majority of participants were women $(n=51)$, from Canada or the United States, and identified themselves as psychologists or research psychologists (Table 1). Participants had been working with cancer survivors for 15 years on average (range 3-37). Sixty-five participants completed Round 1, 43 participants completed Round 2, and 48 participants completed Round 3.

\section{Round 1}

In Round 1, the items "high levels of preoccupation" (75\%) and "high levels of worry" $(80 \%)$ reached consensus as defining features of clinical FCR. Fifty-six additional features of clinical FCR and maladaptive coping strategies were suggested by participants and were grouped into overarching categories (Supplementary file 2). Suggestions included more specific descriptions of the anxiety, fear, and worry related to the possibility that the cancer could return (e.g., "fear is in excess of objective evidence that they are likely to experience a recurrence"); hypervigilance to bodily sensations ("high attention for bodily symptoms and cancer-related issues"), emotional reactions to FCR (e.g., irritability, crying, distress), and a number of 
maladaptive coping strategies (e.g., excessive reassurance seeking, excessive information seeking, substance use, lifestyle changes, behavioural avoidance, and cognitive avoidance) were also suggested. Impaired cognitive processes (i.e., "misinterpretation of symptoms”, "high perceived risk of recurrence"), and various aspects of functional impairment (e.g., difficulties sleeping, changes in roles and relationships etc.) were also suggested by participants as potential defining features of clinical FCR, and were presented for rating in Round 2.

\section{Round 2}

The item "hypervigilance or hypersensitivity to bodily sensations or physical symptoms for signs of cancer recurrence" reached consensus (70\%) as a defining feature of clinical FCR in Round 2. Items related to persistent (67\%), and uncontrollable (65\%) worry, along with the use of maladaptive coping (65\%), impairment in functioning (67.5\%) and difficulties making plans for the future (66\%) approached consensus (Supplementary File 2). Given that they were so close to reaching consensus, these items were presented again in an attempt to clarify experts' views during Round 3.

\section{Round 3}

Based on Rounds 1 and 2, the following items were presented to participants in Round 3: 1) high levels of preoccupation and 2) high levels of worry (reached consensus in Round 1); 3) hypervigilance or hypersensitivity to bodily sensations or physical symptoms for signs of recurrence (reached consensus in Round 2); and 4) uncontrollable worry/fear/anxiety, 5) persistent anxiety/fear/worry, 6) presence of at least one maladaptive coping strategy, 7) impairment in functioning, and 8) difficulties making plans for the future (which were very close to consensus in Round 2). During this final round, persistent anxiety/fear/worry reached consensus (82\%). Impairment in functioning was just below the consensus level with $64 \%$ of 
participants indicating that it must be present to identify clinical FCR. Uncontrollable worry $(60 \%)$, difficulties making plans for the future (27\%) and the use of maladaptive coping strategies $(56 \%)$ remained below the $70 \%$ consensus threshold.

Identifying clinical FCR. The following four items reached the predetermined consensus level: high levels of preoccupation (75\%; Round 1); high levels of worry (80\%; Round 1); hypervigilance or hypersensitivity to bodily sensations or physical symptoms for signs of recurrence (70\%; Round 2); and persistent worry/fear/anxiety (82\%; Round 3).

All participants believed that it is helpful to identify individuals with clinical FCR. The following two features of clinical FCR reached the predetermined consensus level ( $70 \%$ rating 8/10 or higher) as characteristics that must be present to identify clinical FCR: 1) Persistent worry/fear/anxiety (82\%) and; 2) Hypervigilance or hypersensitivity to bodily symptoms for signs of cancer recurrence $(73 \%)$.

The median number of characteristics that must be present for identifying an individual with clinical FCR was 3 (range 2-7; mean 3.42). Twenty-eight participants indicated that the duration should be measured in months, with a median of 3 consecutive months (range 1-12; mean 4.1). Overall, $93 \%$ of participants indicated that they would be comfortable using these criteria to identify cancer survivors with clinical FCR.

Diagnosing clinical FCR. Thirty-two of the 48 (67\%) participants indicated that their profession allows them to communicate diagnoses. Of these participants, $84 \%$ indicated that they believed that diagnosing clinical FCR would be helpful. Persistent worry/fear/anxiety reached consensus as a characteristic that must be present to diagnose clinical FCR (75\%).

On average, these participants thought that a median of 4 characteristics must be present (range 2-6; mean 3.85) for a potential diagnosis of clinical FCR. Most of these participants 
thought the characteristics must be present for a median of 3 months (range 1-12; mean 3.77 months) after removing an outlier of 24 months. Eighty-one percent of the participants who can diagnose indicated that they would be comfortable using these criteria to hypothetically diagnose clinical FCR.

The majority of respondents who could diagnose preferred not to use existing diagnostic criteria to potentially diagnose clinical levels of FCR. Forty-four percent were comfortable applying ICD-11 criteria for Health Anxiety to clinical FCR, 31\% were comfortable applying DSM-5 criteria for IAD, and 25\% were comfortable applying DSM-5 criteria for SSD to clinical FCR.

\section{Discussion}

This study aimed to establish expert consensus on the defining characteristics of clinical FCR. Across three Delphi rounds, high levels of preoccupation and worry, that are persistent, and hypervigilance/hypersensitivity to bodily symptoms reached consensus as the four defining features of clinical FCR. At least three features must be present for at least three months to identify clinical FCR. Impairment in functioning, uncontrollable worry, difficulties making plans for the future, and maladaptive coping strategies were close to consensus and should be considered as potential candidates in future empirical work on defining features of clinical FCR. Most participants who could communicate diagnoses (in their clinical role) indicated the usefulness of diagnosing clinical FCR but did not endorse the application of established diagnostic criteria to clinical FCR.

The features of clinical FCR appear to be related to the severity of the worry/preoccupation (i.e., high levels), the length of time worries and preoccupations are present (i.e., are not transient), and hypersensitivity to bodily symptoms as a trigger. Current FCR 
measures contain items that could be used to assess these features of clinical FCR (FCRI; ${ }^{21}$ Fear of Progression Questionnaire).22

Functional impairment increased from $29 \%$ consensus in Round 1 to near $70 \%$ in Rounds 2 and 3. Considering the overall data, functional impairment may be a broad concept involving too many different components (e.g., impact on sleep, role issues, concentration) to reach consensus. Based on the data it seems that functional impairment may be useful in identifying (66\% agreement) but perhaps not diagnosing (53\% agreement) clinical FCR.

Although the feature 'uncontrollable worry/fear/anxiety' did not reach consensus, this feature may be conceptually related to high levels of persistent preoccupation and worry that did reach consensus. Similar wording among potential features of clinical FCR across Delphi rounds represented an additional challenge in interpretation. For example, it is unclear whether "preoccupation" can be present without "worry," and if preoccupation and worry that is persistent differs meaningfully from "uncontrollable" worry/fear/anxiety. Given the nature of the Delphi method, it was difficult to clearly differentiate these terms as ratings are provided without discussion among participants.

The pattern of results regarding the characteristic "difficulty making plans for the future" was challenging to interpret. It was a suggested feature of clinical FCR at the colloquium on FCR in $2015,{ }^{2}$ did not reach consensus in Round 1, approached consensus in Round 2, but was rated low in the final round as a feature that must be present to identify clinical FCR. Given the lack of clarity around this feature, additional research is needed on the role of planning for the future in the context of FCR in general, and its link to functional impairment.

The majority of suitably qualified participants in this study did not endorse the application of established diagnostic criteria for IAD and SSD from the DSM $5,{ }^{17}$ and HA from 
the ICD- $11^{16}$ to cancer survivors with clinical FCR. Previous work suggests that clinical FCR may share some similarities with, but is a separate construct to anxiety disorders and hypochondriasis. ${ }^{14,15,23}$ It appears that most participants view clinical FCR as a separate construct given that it is specific to cancer, and that it is present due to the experience of actually having cancer and coping with the real possibility of recurrence. Of the three diagnostic labels, HA was endorsed the most, and SSD the least. It appears that HA is a better fit for clinical FCR, but that the focus on the preoccupation with bodily symptoms in SSD does not capture the experience of clinical FCR.

\section{Limitations}

Achieving consensus does not indicate that these are the defining features of clinical FCR. ${ }^{18}$ Additional studies are needed to provide empirical support for these characteristics. Starting the rounds by presenting the five potential features of clinical FCR suggested at the International Colloquium on $\mathrm{FCR}^{2}$ may have influenced the results, resulting in bias in how respondents rated the items. ${ }^{18}$ However, participants had the opportunity to suggest additional features, and the entirety of the second round was based on the suggested features of clinical FCR from participants in Round 1. Ultimately, the authors interpreted the results of each Delphi round which introduces bias into the results.

\section{Clinical Implications}

Currently, a clinician cannot give a formal diagnosis of "clinical FCR" as the criteria to do so have not been defined or approved. However, the characteristics of clinical FCR suggested in this Delphi study can help clinicians and researchers identify and offer interventions to survivors experiencing clinical FCR. The preoccupation, worry and hypervigilance in clinical FCR suggest intervention targets (i.e., mindfulness, cognitive behavioural approaches). ${ }^{24-26}$ 
Consideration of how the characteristics of clinical FCR will be used in clinical practice, and the specific diagnostic label for the presentation of clinical FCR is important. Patient/survivorperspectives on the relevance, usefulness, and impact of a diagnosis of clinical FCR are also important research areas.

We suggest that screening tools for clinical FCR use items related the four features of clinical FCR that reached consensus. Current FCR measures contain potential items, but further refinements are needed. Since current FCR screening measures such as the severity subscale of the FCRI ${ }^{14,21}$ do not assess all of the proposed features of clinical FCR may explain the variability in reported clinical cut-offs. ${ }^{27}$ Future research on the ability of these characteristics to accurately and meaningfully differentiate clinical and non-clinical levels of FCR is recommended (i.e., through structural equation modelling).

\section{Conclusion}

Using a Delphi method, persistently high levels preoccupation/worry and hypervigilance to bodily symptoms reached consensus as defining characteristics of clinical FCR. Future research is required to empirically validate these features of clinical FCR.

Conflict of interest: No

Data available from corresponding author upon reasonable request. 


\section{References}

1. Simard S, Thewes B, Humphris G, Dixon M, Hayden C, Mireskandari S, Ozakicki G. Fear of cancer recurrence in adult cancer survivors: a systematic review of quantitative studies. J Cancer Surviv 2013; 7:300-322.

2. Lebel S, Ozakinci G, Humphris G, Mutsaers B, Thewes B, Prins J, Dinkel A, Butow P, on behalf of the University of Ottawa Fear of Cancer Recurrence Colloquium attendees. From normal response to clinical problem: definition and clinical features of fear of cancer recurrence. Support Care Cancer 2016; 24:3265-3268

3. Dinkel A, Herschbach P. Fear of progression in cancer patients and survivors. In: Goerling, Mehnert A, editors. Psycho-Oncology. Vol. 210. Cham: Springer International Publishing; 2018.

4. Smith AB, Sharpe L, Thewes B, Turner J, Gilchrist J, Fardell J, Girgis A, Tesson S, Descallar J, Bell ML, Butow P, The ConquerFear Authorship Group. Medical, demographic and psychological correlates of fear of cancer recurrence (FCR) morbidity in breast, colorectal and melanoma cancer survivors with probable clinically significant FCR seeking psychological treatment through the ConquerFear study. Support Care Cancer 2018; 26:4207-3216.

5. Lebel S, Tomei C, Feldstain A, Beattie S, McCallum M. Does fear of cancer recurrence predict cancer survivors' health care use? Support Care Cancer 2013; 21:901-906.

6. Champagne A, Ivers H, Savard J. Utilization of health care services in cancer patients with elevated fear of cancer recurrence. Psycho-Oncology 2018; 27:1958-1964.

7. Costa DS. Screening for clinical levels of fear of cancer recurrence. Psycho-Oncology 2017; 26:2002-2003.

8. Lebel S, Ozakinci G, Humphris H, Thewes B, Prins J, Dinkel A, Butow P. Current state and future prospects of research on fear of cancer recurrence. Psycho-Oncology 2016; 26:424-427.

9. Maheu C, Galica J. The fear of cancer recurrence literature continues to move forward: a review article. Curr Opin Support Palliat Care 2018; 12:40-45.

10. Sharpe L, Thewes B, Butow P. Current directions in research and treatment of fear of cancer recurrence. Curr Opin Support Palliat Care 2017; 11:191-196.

11. Custers JA, Gielissen MF, Janssen SH, de Wilt JH, Prins JB. Fear of cancer recurrence in colorectal cancer survivors. Support Care Cancer 2016; 24:555-562.

12. Mutsaers B, Jones G, Rutkowski N, Tomei C, Leclair CS, Petricone-Westwood D, Simard S, Lebel S. When fear of cancer recurrence becomes a clinical issue: a qualitative analysis of features associated with clinical fear of cancer recurrence. Support Care Cancer 2016; 24:4207-4218.

13. Psychology Act (1991, S.O. 1991, c. 38). Retrieved from the Government of Ontario website: https://www.ontario.ca/laws/statute/91p38

14. Simard S, Savard J. Screening and comorbidity of clinical levels of fear of cancer recurrence. J Cancer Surviv 2015; 9:481-491.

15. Dinkel A, Kremsreiter K, Marten-Mittag B, Lahmann C. Comorbidity of fear of progression and anxiety disorders in cancer patients. Gen Hosp Psychiatry 2014; 36:61361.

16. Stein DJ, Kogan CS, Atmaca M, Fineberg NA, Fontenelle LF, Grant JE, Matsunaga H, 
Reddy YCJ, Simpson HB, Thomsen PH, van den Heuvel OA, Veale D, Woods DW, Reed GM. The classification of obsessive-compulsive and related disorders in the ICD11. Journal Affect Disord 2016; 190:663-674.

17. American Psychiatric Association. Diagnostic and statistical manual of mental disorders, fifth edition: DSM-5. Arlington, VA: American Psychiatric Association; 2013.

18. Keeney S, Hasson F, McKenna H. The Delphi technique in nursing and health research. Chichester, West-Sussex: Wiley-Blackwell; 2011.

19. Keeney S, Hasson F, McKenna H. Consulting the oracle: ten lessons from using the Delphi technique in nursing research. J Adv Nurs 2006; 53:205-212.

20. Hsieh HF, Shannon SE. Three approaches to qualitative content analysis. Qual Health Res 2005; 15:1277-1288.

21. Simard S, Savard J. Fear of cancer recurrence inventory: Development and initial validation of a multidimensional measure of fear of recurrence. Support Care Cancer 2009; 17:241-251.

22. Herschbach P, Berg P, Dankert A, Duran G, Engst-Hastreiter U, Waadt S, Keller M, Ukat R, Henrich G. Fear of progression in chronic diseases: psychometric properties of the Fear of Progression Questionnaire. J Psychosom Res 2005; 58:505-511.

23. Thewes B, Bell ML, Butow P, Beith J, Boyle F, Friedlander M, McLachlan SA. Psychological morbidity and stress but not social factors influence level of fear of cancer recurrence in young women with early breast cancer: results of a cross-sectional study. Psycho-Oncology 2013; 22:2797-2806.

24. Hall DL, Luberto CM, Philpotts LL, Song R, Park ER, \& Yeh, G.Y. Mind-body interventions for fear of cancer recurrence: A systematic review and meta-analysis. Psycho-Oncology 2018; 27: 2546-2558.

25. Zhang, J, Xu R, Wang B, Wang J. Effects of mindfulness-based therapy for patients with breast cancer: a systematic review and meta-analysis. Complementary Therapies in Medicine 2016; 1-10.

26. Tauber NM, O'Toole MS, Dinkel A, Galica J, Humphris G, Lebel S, Maheu C, Ozakinci G, Prins J, Sharpe L, Smith AB. Effect of psychological intervention on fear of cancer recurrence: a systematic review and meta-analysis. Journal of Clinical Oncology 2019; In press.

27. Fardell JE, Jones G, Smith AB, Lebel S, Thewes B, Costa D, Tiller K, Simard S, Feldstain A, Beattie S, McCallum M. Exploring the screening capacity of the Fear of Cancer Recurrence Inventory-Short Form for clinical levels of fear of cancer recurrence. Psycho-Oncology 2018;27:492-9. 
Table 1. Participant professions and geographical locations

\begin{tabular}{ll|ll}
\hline Profession & \# participants & Geographical location & \# participants \\
\hline Physician & 5 & Africa & 2 \\
Psychologist & 23 & Asia & 3 \\
Researcher & 6 & Australia \& New Zealand & 10 \\
Researcher, Nurse & 3 & Canada & 12 \\
Researcher, Physician & 3 & Europe & 16 \\
Researcher, Psychologist & 18 & South America & 2 \\
Nurse & 2 & United Kingdom & 7 \\
Social worker & 4 & United States & 13 \\
Other allied health & 1 & & \\
professional & & & \\
\hline
\end{tabular}


Identifying the Key Characteristics of Clinical Fear of Cancer Recurrence: An International

Delphi Study

Brittany Mutsaers ${ }^{*}$, Phyllis Butow ${ }^{2}$, Andreas Dinkel $^{3}$, Gerald Humphris ${ }^{4}$, Christine Maheu 5 , Gozde Ozakinci ${ }^{4}$, Judith Prins ${ }^{6}$, Louise Sharpe ${ }^{2}$, Allan "Ben” Smith, Belinda Thewes ${ }^{2}$ \& Sophie Lebel $^{1}$.

${ }^{1}$ University of Ottawa, Ottawa ON, Canada

${ }^{2}$ School of Psychology, The University of Sydney, Australia

${ }^{3}$ Department of Psychosomatic Medicine and Psychotherapy, Klinikum rechts der Isar, Technical University of Munich, Germany

${ }^{4}$ School of Medicine, University of St Andrews, United Kingdom

${ }^{5}$ McGill University, Canada

${ }^{6}$ Radboud University, Netherlands

${ }^{7}$ Centre for Oncology Education \& Research Translation (CONCERT), Ingham Institute for Applied Medical Research, South Western Sydney Clinical School, UNSW, Sydney, Australia

* Corresponding author

Brittany Mutsaers

University of Ottawa

136 Jean Jacques Lussier PVT

Ottawa, ON

bmuts031@uottawa.ca 


\begin{abstract}
Objective: Without an agreed-upon set of characteristics that differentiate clinical from nonclinical levels of fear of cancer recurrence (FCR), it is difficult to ensure that FCR severity is appropriately measured, and that those in need of intervention are identified. The objective of this study was to establish expert consensus on the defining features of clinical FCR.

Method: A three-round Delphi was used to reach consensus on the defining features of clinical FCR. Sixty-five experts in FCR (researchers, psychologists, physicians, nurses, allied health professionals) were recruited to suggest and rate potential features of clinical FCR. Participants who indicated they could communicate diagnoses within their clinical role were also asked to consider the application of established DSM-5 and proposed ICD-11 diagnostic criteria (Health Anxiety, Illness Anxiety Disorder, Somatic Symptom Disorder) to clinical FCR.

Results: Participants' ratings suggested that the following 4 features are key characteristics of clinical FCR: 1) high levels of preoccupation; 2) high levels of worry; 3) that are persistent; and 4) hypervigilance to bodily symptoms. Of participants whose professional role allowed them to diagnose mental disorders $84 \%$ indicated it would be helpful to diagnose clinical FCR, but the use of established diagnostic criteria related to health anxiety or somatic-related disorders to clinical FCR was not supported. This suggests that participants consider clinical FCR as a presentation that is specific to cancer survivors.
\end{abstract}

Conclusion: Clinical FCR was conceptualized as a multi-dimensional construct. Further research is needed to empirically validate the proposed defining features.

Keywords: cancer; oncology; definition; Delphi; expert consensus; fear of cancer recurrence 
Fear of cancer recurrence (FCR) impacts most cancer survivors ${ }^{1}$ and is defined as the "the fear, worry or concern relating to the possibility that cancer will come back or progress."2, p. 3266 Given the implications of a cancer diagnosis and treatment, experiencing FCR is reasonable and expected. ${ }^{3}$ While FCR can be adaptive, ${ }^{2,3,4}$ when it is experienced at high levels of severity it leads to significant distress, decreased quality of life, ${ }^{1}$ and increased health-care use. ${ }^{5,6}$ The lack of established characteristics that differentiate normative from clinically severe FCR is a gap in FCR research, ${ }^{2,7-10}$ since these characteristics would facilitate the accurate measurement of FCR severity, the severity of FCR requiring intervention, and appropriate intervention intensity. ${ }^{7,9,10}$

Previous work has been conducted on identifying potential features of clinical FCR. For example, items more commonly endorsed by respondents considered to have clinical FCR on the Fear of Cancer Recurrence Inventory (FCRI) ${ }^{11}$ included: experiencing fear, worry, and anxiety; functional impairment; and frequently thinking about the negative impact that a cancer recurrence would have on one's life. ${ }^{11}$ Similarly, qualitatively analysed interviews with 40 breast, lung, colorectal, and prostate cancer survivors identified the following potential features of clinical FCR: death-related thoughts; feeling alone; belief that the cancer will return; intolerance of uncertainty; recurrent thoughts and images lasting at least 30 minutes, occur daily, are difficult to control, and cause distress; and impairment in functioning. ${ }^{12}$ The next step in FCR research is to establish consensus on the defining features of clinical FCR. ${ }^{2,7,8}$

Preliminary work on establishing consensus on the defining features of clinical FCR was conducted at an International Colloquium in 2015 at the University of Ottawa. ${ }^{2,8}$ Using one round of rating potential features of clinical FCR, 12 clinicians/clinician-researchers, 10 trainees with FCR research experience, one government funded cancer survivorship organization representative, and two patient representatives who attended the colloquium identified five 
potential features of clinical FCR. These were: 1) high levels of preoccupation, worry, rumination, or intrusive thoughts; 2) maladaptive coping (e.g., excessive reassurance seeking, avoidance); 3) functional impairment; 4) excessive distress; and 5) difficulties making plans for the future. ${ }^{2}$

To extend this work, a larger-scale Delphi study was needed to reach expert consensus on the defining features of clinical FCR. Further, consensus was needed regarding the number of features and for how long they must be present to identify clinical FCR in a cancer survivor. When considering defining features of clinical FCR, an important distinction between identifying and diagnosing clinical FCR must be made. Identifying cancer survivors with clinical FCR based on the presence of certain features for research purposes, coordinating care, providing services, etc. can be done by researchers and health care professionals, as appropriate. In contrast, communicating a diagnosis is considered a controlled act, and can only be done by specific professionals within their clinical role (e.g., in Canada, Psychology Act, 1991). ${ }^{13}$ Given the stigma associated with a diagnosis of a mental health condition and the normative response of FCR among cancer survivors, it was important to obtain expert consensus on whether clinical FCR should potentially be considered a "diagnosis." 8

When FCR is experienced at clinical levels, presenting symptoms may be similar to established diagnostic criteria for mental disorders, including anxiety disorders and hypochondriasis. ${ }^{14-15}$ Although the authors found some overlap between these disorders and FCR, ${ }^{14-15}$ newer, health-related diagnoses have been proposed that may be a better fit. The proposed diagnostic criteria for Health Anxiety (HA) in the upcoming eleventh edition of the International Classification of Diseases (ICD-11) appear to overlap with the defining characteristics of clinical FCR proposed at the FCR colloquium (Supplementary File 1). ${ }^{2,16}$ 
Based on this, consideration of established health-specific diagnostic criteria that are potentially related to clinical FCR, including ICD-11 criteria for Health Anxiety ${ }^{16}$ and the Diagnostic and Statistical Manual of Mental Disorders, Fifth Edition (DSM-5) ${ }^{17}$ criteria for Illness Anxiety Disorder (IAD) and Somatic Symptom Disorder (SSD), ${ }^{17}$ was pertinent and has not been previously proposed.

The present study was a formal Delphi on the defining features of clinical FCR that aimed to: 1) reach expert consensus on the characteristics that differentiate clinical from nonclinical FCR; 2) examine experts' views on using these features to a) identify and b) diagnose cancer survivors with clinical FCR; and 3) explore experts' views on applying already established diagnostic criteria (i.e., HA, IAD, and SSD) to clinical FCR.

\section{Method}

\section{Participants}

As the purpose of this study was to establish consensus on the defining features of clinical FCR, participants needed to have some expertise related to FCR. The inclusion criteria for expert participants were: 1) researchers (who have authored/co-authored a peer reviewed article on FCR within the last five years); 2) nurses, social workers, physicians, psychologists, or other allied health professionals (with at least five years of experience working with cancer survivors); 3) able to read and write in English; 4) access to a computer with an internet connection and; 5) willing to provide an email address to receive Rounds 2 and 3 of the Delphi study questionnaires.

Participants were recruited via email through professional organizations related to psycho-oncology and cancer survivorship, through contacting authors of recently published articles on FCR, and through snowball sampling (i.e., encouraging those who received the 
recruitment emails to forward it to colleagues who may be interested in participating). There are no clear guidelines published regarding the number of participants needed in Delphi studies, ${ }^{18}$ but the goal was to recruit a minimum of 50 participants in Round 1 in order to account for potential dropout across the three Delphi rounds. ${ }^{18}$

\section{Procedure}

Round 1. Qualtrics survey software was used to distribute and collect the data from the Delphi rounds. A link to the first of three Delphi rounds was included in the recruitment email. The Round 1 questionnaire contained a brief socio-demographic and eligibility-screening questionnaire. Those who did not meet the inclusion criteria did not complete the subsequent questionnaires. Participants were then presented with the suggested characteristics of clinical FCR from the International Colloquium on FCR and were asked to rate the extent to which they thought each item was characteristic of clinical FCR using a 10-point rating scale where 0 indicated the item "is not a characteristic of clinical FCR" and 10 indicated the item "is a characteristic of clinical FCR." In this round, participants also had the opportunity to list up to five additional characteristics of clinical FCR and up to five additional maladaptive coping strategies associated with clinical FCR. From a methodological standpoint, presenting previously suggested items of clinical FCR focused the additional suggestions, which streamlined the analysis by making the volume of suggestions more manageable. ${ }^{18}$

Participants were also asked to consider whether the item "difficulty making plans for the future" from the results of the Delphi conducted at the International Colloquium on FCR should be considered a standalone feature of clinical FCR or an aspect of functional impairment. This question was included because impairment in functioning could encompass difficulties making plans for the future. ${ }^{2}$ 
Consensus. There are multiple ways in which consensus can be defined for Delphi studies, and thus it is recommended that a consensus rating be established before the start of the Delphi rounds. ${ }^{18}$ For the present study, a characteristic of clinical FCR was considered to have reached consensus when at least $70 \%$ of participants rated the item $8 / 10$ or higher. Using a high cut-off of eight on a ten point rating scale was chosen to avoid obtaining features that could apply to cancer survivors who are not experiencing clinically significant levels of FCR. A consensus level of $70 \%$ of participants rating the item $8 / 10$ or higher for specific features of clinical FCR to be retained was chosen to be both conservative, and to ensure that consensus would be reached (i.e., a consensus level of $100 \%$ is not feasible). ${ }^{19}$

The results from Round 1 were summarized by calculating the percent of participants who rated each item $8 / 10$ or higher. For the Yes/No and fixed response option questions, the percentage of participants choosing each response option was calculated. Content analysis was used to summarize participants' responses to open-ended questions. Similar statements across participants were grouped together and a summary statement for each group was assigned to represent the overall meaning of the responses. ${ }^{18,20}$ The content analysis was conducted by hand by the first author and checked by the last author. Data collection for Round 1 occurred from February 1, 2018 to March 30, 2018.

Round 2. The items from Round 1 that reached consensus were presented to participants along with the content analysed suggestions of additional potential features of clinical FCR from Round 1. In Round 2, participants were asked to rate these additional potential features of clinical FCR as in Round 1, using the same 10-point rating scales.

The results of Round 2 were analyzed by calculating the percentage of participants rating each item 8/10 or higher. The data were collected for Round 2 from April 30 to May 21, 2018. 
Round 3. The final Delphi round consisted of three sections focused on: 1) identifying individuals with clinical FCR; 2) diagnosing individuals with clinical FCR; and 3) applying previously established diagnostic criteria to clinical FCR.

Specifically, participants were asked to indicate whether they believed that it would be useful to identify individuals with clinical FCR. Those who responded 'Yes' were presented with the items that reached consensus from the first two Delphi rounds. Participants were then asked to indicate which of the characteristics, how many characteristics, and the duration that these characteristics need to be present to warrant the identification of clinical FCR in a cancer survivor.

Participants were then asked to indicate whether they could communicate a diagnosis in their profession.* Only those who answered yes completed the remainder of Round 3. These participants were then asked to indicate whether they thought it would be helpful to diagnose clinical FCR. Those who responded 'Yes' were presented with the items that reached consensus in the previous two rounds. Participants were then asked to indicate which of these features, how many, and the duration required to warrant a diagnosis of clinical FCR. Descriptive statistics were calculated (mean, median, range) for the number of characteristics and the duration of time each characteristic must be present in order to identify and/or diagnose an individual with clinical FCR.

The final section of Round 3 asked participants to consider the applicability of the upcoming ICD-11 criteria for Health Anxiety, and the DSM-5 criteria for IAD and SSD to clinical FCR. The diagnostic criteria for these three disorders were presented to participants, who

\footnotetext{
${ }^{*}$ The controlled act of communicating a diagnosis is only applicable to specific professions. ${ }^{13}$ When considering a hypothetical diagnosis of clinical FCR only those who could diagnose within their professional role were included in this section.
} 
were then asked to indicate whether or not they would feel comfortable using these diagnostic criteria to diagnose an individual with clinical FCR. The percentage of participants responding 'Yes' was calculated for these questions (Supplementary Figure 1, Supplementary files 1 and 2).

\section{Ethical Approval}

Ethical approval was provided by the University of Ottawa Research Ethics Board (H08-17-45). The consent form was presented first upon clicking the Round 1 questionnaire link. Participants provided consent by clicking "I consent."

\section{Results}

\section{Participants}

Sixty-five experts participated in the first Delphi round. The majority of participants were women $(n=51)$, from Canada or the United States, and identified themselves as psychologists or research psychologists (Table 1). Participants had been working with cancer survivors for 15 years on average (range 3-37). Sixty-five participants completed Round 1, 43 participants completed Round 2, and 48 participants completed Round 3.

\section{Round 1}

In Round 1, the items "high levels of preoccupation" (75\%) and "high levels of worry" $(80 \%)$ reached consensus as defining features of clinical FCR. Fifty-six additional features of clinical FCR and maladaptive coping strategies were suggested by participants and were grouped into overarching categories (Supplementary file 2). Suggestions included more specific descriptions of the anxiety, fear, and worry related to the possibility that the cancer could return (e.g., "fear is in excess of objective evidence that they are likely to experience a recurrence"); hypervigilance to bodily sensations ("high attention for bodily symptoms and cancer-related issues"), emotional reactions to FCR (e.g., irritability, crying, distress), and a number of 
maladaptive coping strategies (e.g., excessive reassurance seeking, excessive information seeking, substance use, lifestyle changes, behavioural avoidance, and cognitive avoidance) were also suggested. Impaired cognitive processes (i.e., "misinterpretation of symptoms", "high perceived risk of recurrence"), and various aspects of functional impairment (e.g., difficulties sleeping, changes in roles and relationships etc.) were also suggested by participants as potential defining features of clinical FCR, and were presented for rating in Round 2.

\section{Round 2}

The item "hypervigilance or hypersensitivity to bodily sensations or physical symptoms for signs of cancer recurrence" reached consensus (70\%) as a defining feature of clinical FCR in Round 2. Items related to persistent (67\%), and uncontrollable (65\%) worry, along with the use of maladaptive coping (65\%), impairment in functioning (67.5\%) and difficulties making plans for the future (66\%) approached consensus (Supplementary File 2). Given that they were so close to reaching consensus, these items were presented again in an attempt to clarify experts' views during Round 3.

\section{Round 3}

Based on Rounds 1 and 2, the following items were presented to participants in Round 3: 1) high levels of preoccupation and 2) high levels of worry (reached consensus in Round 1); 3) hypervigilance or hypersensitivity to bodily sensations or physical symptoms for signs of recurrence (reached consensus in Round 2); and 4) uncontrollable worry/fear/anxiety, 5) persistent anxiety/fear/worry, 6) presence of at least one maladaptive coping strategy, 7) impairment in functioning, and 8) difficulties making plans for the future (which were very close to consensus in Round 2). During this final round, persistent anxiety/fear/worry reached consensus (82\%). Impairment in functioning was just below the consensus level with $64 \%$ of 
participants indicating that it must be present to identify clinical FCR. Uncontrollable worry $(60 \%)$, difficulties making plans for the future (27\%) and the use of maladaptive coping strategies $(56 \%)$ remained below the $70 \%$ consensus threshold.

Identifying clinical FCR. The following four items reached the predetermined consensus level: high levels of preoccupation (75\%; Round 1); high levels of worry (80\%; Round 1); hypervigilance or hypersensitivity to bodily sensations or physical symptoms for signs of recurrence (70\%; Round 2); and persistent worry/fear/anxiety (82\%; Round 3).

All participants believed that it is helpful to identify individuals with clinical FCR. The following two features of clinical FCR reached the predetermined consensus level $(70 \%$ rating 8/10 or higher) as characteristics that must be present to identify clinical FCR: 1) Persistent worry/fear/anxiety (82\%) and; 2) Hypervigilance or hypersensitivity to bodily symptoms for signs of cancer recurrence $(73 \%)$.

The median number of characteristics that must be present for identifying an individual with clinical FCR was 3 (range 2-7; mean 3.42). Twenty-eight participants indicated that the duration should be measured in months, with a median of 3 consecutive months (range 1-12; mean 4.1). Overall, $93 \%$ of participants indicated that they would be comfortable using these criteria to identify cancer survivors with clinical FCR.

Diagnosing clinical FCR. Thirty-two of the 48 (67\%) participants indicated that their profession allows them to communicate diagnoses. Of these participants, $84 \%$ indicated that they believed that diagnosing clinical FCR would be helpful. Persistent worry/fear/anxiety reached consensus as a characteristic that must be present to diagnose clinical FCR (75\%).

On average, these participants thought that a median of 4 characteristics must be present (range 2-6; mean 3.85) for a potential diagnosis of clinical FCR. Most of these participants 
thought the characteristics must be present for a median of 3 months (range 1-12; mean 3.77 months) after removing an outlier of 24 months. Eighty-one percent of the participants who can diagnose indicated that they would be comfortable using these criteria to hypothetically diagnose clinical FCR.

The majority of respondents who could diagnose preferred not to use existing diagnostic criteria to potentially diagnose clinical levels of FCR. Forty-four percent were comfortable applying ICD-11 criteria for Health Anxiety to clinical FCR, 31\% were comfortable applying DSM-5 criteria for IAD, and 25\% were comfortable applying DSM-5 criteria for SSD to clinical FCR.

\section{Discussion}

This study aimed to establish expert consensus on the defining characteristics of clinical FCR. Across three Delphi rounds, high levels of preoccupation and worry, that are persistent, and hypervigilance/hypersensitivity to bodily symptoms reached consensus as the four defining features of clinical FCR. At least three features must be present for at least three months to identify clinical FCR. Impairment in functioning, uncontrollable worry, difficulties making plans for the future, and maladaptive coping strategies were close to consensus and should be considered as potential candidates in future empirical work on defining features of clinical FCR. Most participants who could communicate diagnoses (in their clinical role) indicated the usefulness of diagnosing clinical FCR but did not endorse the application of established diagnostic criteria to clinical FCR.

The features of clinical FCR appear to be related to the severity of the worry/preoccupation (i.e., high levels), the length of time worries and preoccupations are present (i.e., are not transient), and hypersensitivity to bodily symptoms as a trigger. Current FCR 
measures contain items that could be used to assess these features of clinical FCR (FCRI; ${ }^{21}$ Fear of Progression Questionnaire).22

Functional impairment increased from $29 \%$ consensus in Round 1 to near $70 \%$ in Rounds 2 and 3. Considering the overall data, functional impairment may be a broad concept involving too many different components (e.g., impact on sleep, role issues, concentration) to reach consensus. Based on the data it seems that functional impairment may be useful in identifying (66\% agreement) but perhaps not diagnosing (53\% agreement) clinical FCR.

Although the feature 'uncontrollable worry/fear/anxiety' did not reach consensus, this feature may be conceptually related to high levels of persistent preoccupation and worry that did reach consensus. Similar wording among potential features of clinical FCR across Delphi rounds represented an additional challenge in interpretation. For example, it is unclear whether "preoccupation" can be present without "worry," and if preoccupation and worry that is persistent differs meaningfully from "uncontrollable" worry/fear/anxiety. Given the nature of the Delphi method, it was difficult to clearly differentiate these terms as ratings are provided without discussion among participants.

The pattern of results regarding the characteristic "difficulty making plans for the future" was challenging to interpret. It was a suggested feature of clinical FCR at the colloquium on FCR in 2015, ${ }^{2}$ did not reach consensus in Round 1, approached consensus in Round 2, but was rated low in the final round as a feature that must be present to identify clinical FCR. Given the lack of clarity around this feature, additional research is needed on the role of planning for the future in the context of FCR in general, and its link to functional impairment.

The majority of suitably qualified participants in this study did not endorse the application of established diagnostic criteria for IAD and SSD from the DSM $5,{ }^{17}$ and HA from 
the ICD- $11^{16}$ to cancer survivors with clinical FCR. Previous work suggests that clinical FCR may share some similarities with, but is a separate construct to anxiety disorders and hypochondriasis. ${ }^{14,15,23}$ It appears that most participants view clinical FCR as a separate construct given that it is specific to cancer, and that it is present due to the experience of actually having cancer and coping with the real possibility of recurrence. Of the three diagnostic labels, HA was endorsed the most, and SSD the least. It appears that HA is a better fit for clinical FCR, but that the focus on the preoccupation with bodily symptoms in SSD does not capture the experience of clinical FCR.

\section{Limitations}

Achieving consensus does not indicate that these are the defining features of clinical FCR. ${ }^{18}$ Additional studies are needed to provide empirical support for these characteristics. Starting the rounds by presenting the five potential features of clinical FCR suggested at the International Colloquium on $\mathrm{FCR}^{2}$ may have influenced the results, resulting in bias in how respondents rated the items. ${ }^{18}$ However, participants had the opportunity to suggest additional features, and the entirety of the second round was based on the suggested features of clinical FCR from participants in Round 1. Ultimately, the authors interpreted the results of each Delphi round which introduces bias into the results.

\section{Clinical Implications}

Currently, a clinician cannot give a formal diagnosis of "clinical FCR" as the criteria to do so have not been defined or approved. However, the characteristics of clinical FCR suggested in this Delphi study can help clinicians and researchers identify and offer interventions to survivors experiencing clinical FCR. The preoccupation, worry and hypervigilance in clinical FCR suggest intervention targets (i.e., mindfulness, cognitive behavioural approaches). ${ }^{24-26}$ 
Consideration of how the characteristics of clinical FCR will be used in clinical practice, and the specific diagnostic label for the presentation of clinical FCR is important. Patient/survivorperspectives on the relevance, usefulness, and impact of a diagnosis of clinical FCR are also important research areas.

We suggest that screening tools for clinical FCR use items related the four features of clinical FCR that reached consensus. Current FCR measures contain potential items, but further refinements are needed. Since current FCR screening measures such as the severity subscale of the FCRI ${ }^{14,21}$ do not assess all of the proposed features of clinical FCR may explain the variability in reported clinical cut-offs. ${ }^{27}$ Future research on the ability of these characteristics to accurately and meaningfully differentiate clinical and non-clinical levels of FCR is recommended (i.e., through structural equation modelling).

\section{Conclusion}

Using a Delphi method, persistently high levels preoccupation/worry and hypervigilance to bodily symptoms reached consensus as defining characteristics of clinical FCR. Future research is required to empirically validate these features of clinical FCR.

Conflict of interest: No

Data available from corresponding author upon reasonable request. 


\section{References}

1. Simard S, Thewes B, Humphris G, Dixon M, Hayden C, Mireskandari S, Ozakicki G. Fear of cancer recurrence in adult cancer survivors: a systematic review of quantitative studies. J Cancer Surviv 2013; 7:300-322.

2. Lebel S, Ozakinci G, Humphris G, Mutsaers B, Thewes B, Prins J, Dinkel A, Butow P, on behalf of the University of Ottawa Fear of Cancer Recurrence Colloquium attendees. From normal response to clinical problem: definition and clinical features of fear of cancer recurrence. Support Care Cancer 2016; 24:3265-3268

3. Dinkel A, Herschbach P. Fear of progression in cancer patients and survivors. In: Goerling, Mehnert A, editors. Psycho-Oncology. Vol. 210. Cham: Springer International Publishing; 2018.

4. Smith AB, Sharpe L, Thewes B, Turner J, Gilchrist J, Fardell J, Girgis A, Tesson S, Descallar J, Bell ML, Butow P, The ConquerFear Authorship Group. Medical, demographic and psychological correlates of fear of cancer recurrence (FCR) morbidity in breast, colorectal and melanoma cancer survivors with probable clinically significant FCR seeking psychological treatment through the ConquerFear study. Support Care Cancer 2018; 26:4207-3216.

5. Lebel S, Tomei C, Feldstain A, Beattie S, McCallum M. Does fear of cancer recurrence predict cancer survivors' health care use? Support Care Cancer 2013; 21:901-906.

6. Champagne A, Ivers H, Savard J. Utilization of health care services in cancer patients with elevated fear of cancer recurrence. Psycho-Oncology 2018; 27:1958-1964.

7. Costa DS. Screening for clinical levels of fear of cancer recurrence. Psycho-Oncology 2017; 26:2002-2003.

8. Lebel S, Ozakinci G, Humphris H, Thewes B, Prins J, Dinkel A, Butow P. Current state and future prospects of research on fear of cancer recurrence. Psycho-Oncology 2016; 26:424-427.

9. Maheu C, Galica J. The fear of cancer recurrence literature continues to move forward: a review article. Curr Opin Support Palliat Care 2018; 12:40-45.

10. Sharpe L, Thewes B, Butow P. Current directions in research and treatment of fear of cancer recurrence. Curr Opin Support Palliat Care 2017; 11:191-196.

11. Custers JA, Gielissen MF, Janssen SH, de Wilt JH, Prins JB. Fear of cancer recurrence in colorectal cancer survivors. Support Care Cancer 2016; 24:555-562.

12. Mutsaers B, Jones G, Rutkowski N, Tomei C, Leclair CS, Petricone-Westwood D, Simard S, Lebel S. When fear of cancer recurrence becomes a clinical issue: a qualitative analysis of features associated with clinical fear of cancer recurrence. Support Care Cancer 2016; 24:4207-4218.

13. Psychology Act (1991, S.O. 1991, c. 38). Retrieved from the Government of Ontario website: https://www.ontario.ca/laws/statute/91p38

14. Simard S, Savard J. Screening and comorbidity of clinical levels of fear of cancer recurrence. J Cancer Surviv 2015; 9:481-491.

15. Dinkel A, Kremsreiter K, Marten-Mittag B, Lahmann C. Comorbidity of fear of progression and anxiety disorders in cancer patients. Gen Hosp Psychiatry 2014; 36:61361.

16. Stein DJ, Kogan CS, Atmaca M, Fineberg NA, Fontenelle LF, Grant JE, Matsunaga H, 
Reddy YCJ, Simpson HB, Thomsen PH, van den Heuvel OA, Veale D, Woods DW, Reed GM. The classification of obsessive-compulsive and related disorders in the ICD11. Journal Affect Disord 2016; 190:663-674.

17. American Psychiatric Association. Diagnostic and statistical manual of mental disorders, fifth edition: DSM-5. Arlington, VA: American Psychiatric Association; 2013.

18. Keeney S, Hasson F, McKenna H. The Delphi technique in nursing and health research. Chichester, West-Sussex: Wiley-Blackwell; 2011.

19. Keeney S, Hasson F, McKenna H. Consulting the oracle: ten lessons from using the Delphi technique in nursing research. J Adv Nurs 2006; 53:205-212.

20. Hsieh HF, Shannon SE. Three approaches to qualitative content analysis. Qual Health Res 2005; 15:1277-1288.

21. Simard S, Savard J. Fear of cancer recurrence inventory: Development and initial validation of a multidimensional measure of fear of recurrence. Support Care Cancer 2009; 17:241-251.

22. Herschbach P, Berg P, Dankert A, Duran G, Engst-Hastreiter U, Waadt S, Keller M, Ukat R, Henrich G. Fear of progression in chronic diseases: psychometric properties of the Fear of Progression Questionnaire. J Psychosom Res 2005; 58:505-511.

23. Thewes B, Bell ML, Butow P, Beith J, Boyle F, Friedlander M, McLachlan SA. Psychological morbidity and stress but not social factors influence level of fear of cancer recurrence in young women with early breast cancer: results of a cross-sectional study. Psycho-Oncology 2013; 22:2797-2806.

24. Hall DL, Luberto CM, Philpotts LL, Song R, Park ER, \& Yeh, G.Y. Mind-body interventions for fear of cancer recurrence: A systematic review and meta-analysis. Psycho-Oncology 2018; 27: 2546-2558.

25. Zhang, J, Xu R, Wang B, Wang J. Effects of mindfulness-based therapy for patients with breast cancer: a systematic review and meta-analysis. Complementary Therapies in Medicine 2016; 1-10.

26. Tauber NM, O'Toole MS, Dinkel A, Galica J, Humphris G, Lebel S, Maheu C, Ozakinci G, Prins J, Sharpe L, Smith AB. Effect of psychological intervention on fear of cancer recurrence: a systematic review and meta-analysis. Journal of Clinical Oncology 2019; In press.

27. Fardell JE, Jones G, Smith AB, Lebel S, Thewes B, Costa D, Tiller K, Simard S, Feldstain A, Beattie S, McCallum M. Exploring the screening capacity of the Fear of Cancer Recurrence Inventory-Short Form for clinical levels of fear of cancer recurrence. Psycho-Oncology 2018;27:492-9. 
2

3

6

7

8

Table 1. Participant professions and geographical locations

\begin{tabular}{ll|ll}
\hline Profession & \# participants & Geographical location & \# participants \\
\hline Physician & 5 & Africa & 2 \\
Psychologist & 23 & Asia & 3 \\
Researcher & 6 & Australia \& New Zealand & 10 \\
Researcher, Nurse & 3 & Canada & 12 \\
Researcher, Physician & 3 & Europe & 16 \\
Researcher, Psychologist & 18 & South America & 2 \\
Nurse & 2 & United Kingdom & 7 \\
Social worker & 4 & United States & 13 \\
Other allied health & 1 & & \\
professional & & & \\
\hline
\end{tabular}


1

2

3

4

5

6

7

8

9

10

11

12

13

14

15

16

17

18

19

20

21

22

23

24

25

28

29

30

31

32

33

34

35

36

44

45

46

47

48

49

50

51

52

53

54

55

56

57

58

59

60

http://mc.manuscriptcentral.com/pon 
- Socio-demographic questionnaire

\begin{tabular}{c|l}
$\underset{n=65}{\text { Round } 1}$ & - Rating 5 features from Colloquium on FCR \\
& - Suggest up to 5 additional maladaptive coping strategies
\end{tabular}

- Suggest up to 5 additional characteristics of clinical FCR

- Consider whether difficulty making plans for the future as a standalone feature or part of functional impairment

\begin{tabular}{|c|c|}
\hline $\begin{array}{c}\text { Round } 2 \\
n=43\end{array}$ & $\begin{array}{l}\text { - Participants presented with the features of clinical FCR that reached consensus in } \\
\text { Round } 1 \\
\text { - Rating additional features and maladaptive coping strategies suggested in Round } 1\end{array}$ \\
\hline $\begin{array}{c}\text { Round } 3 \\
n=48\end{array}$ & $\begin{array}{l}\text { Part 1 } \\
\text { - Participants presented with the features of clinical FCR that reached consensus in the } \\
\text { two previous rounds, and items from Round } 2 \text { that approached consensus. } \\
\text { - Participants asked to consider the item that reached consensus and indicate } \\
\circ \text { Which of the features must be present to identify clinical FCR } \\
\circ \text { How many of the features must be present to identify clinical FCR } \\
\circ \text { Duration of time the features must be present to identify clinical FCR } \\
\circ \text { Comfort with using these features to identify clinical FCR }\end{array}$ \\
\hline \multirow[t]{2}{*}{$\begin{array}{c}\text { Round } 3 \\
n=32\end{array}$} & $\begin{array}{l}\text { Part } 2 \\
\text { - Participants presented with the features of clinical FCR that reached consensus in the } \\
\text { two previous rounds, and items from Round } 2 \text { that approached consensus. } \\
\text { Participants asked to consider the item that reached consensus and indicate } \\
\circ \text { Which of the features must be present to diagnose clinical FCR } \\
\circ \text { How many of the features must be present to diagnose clinical FCR } \\
\circ \text { Duration of time the features must be present to diagnose clinical FCR } \\
\circ \text { Comfort with using these features to diagnose clinical FCR }\end{array}$ \\
\hline & $\begin{array}{l}\text { Part } 3 \\
\text { - Participants asked to indicate whether or not they would be comfortable using the } \\
\text { diagnostic criteria for Health Anxiety from the upcoming ICD-11, Illness Anxiety } \\
\text { Disorder and Somatic Symptom Disorder from the DSM-5 }\end{array}$ \\
\hline
\end{tabular}

$215 \times 279 \mathrm{~mm}(150 \times 150 \mathrm{DPI})$ 


\section{Supplementary File 1 Structure of the Delphi Rounds}

\section{Round 1}

\section{Clinical FCR Delphi Questionnaire}

In August 2015, a Fear of Cancer Recurrence Colloquium was held at the University of Ottawa. During this time, experts in the field of Fear of Cancer Recurrence (FCR), including clinicians and researchers participated in an informal Delphi study where potential features of clinical FCR were proposed (Lebel et al., 2016).

The following 5 features were suggested:

- High levels of preoccupation, worry, rumination or intrusive thoughts

- Maladaptive coping

- Functional impairments

- Excessive distress

- Difficulty making plans for the future

The purpose of this Delphi study is to identify the defining features of clinical FCR for research and/or diagnostic purposes. The present study will have three rounds: Rounds 1 and 2 will focus on characteristics of clinical FCR and Round 3 will focus on the defining features of clinical FCR that MUST be present in order for an individual to be considered to be experiencing FCR at a clinical level. Additionally, in Round 3 we will explore the possibility of employing predefined diagnostic criteria to identify individuals with clinical FCR.

Please respond to the following questions regarding the characteristics of clinical FCR.

\begin{tabular}{|c|c|}
\hline Question & Response Option \\
\hline \multicolumn{2}{|c|}{ Please rate how much you think each criteria is a characteristic of clinical FCR: } \\
\hline High levels of preoccupation & \multirow{10}{*}{$\begin{array}{l}\text { 10-point visual analogue scale } \\
0 \text { - "Is not a characteristic of clinical FCR" } \\
10 \text { - "Is a characteristic of clinical FCR" }\end{array}$} \\
\hline High levels of worry & \\
\hline High levels of rumination & \\
\hline High levels of intrusive thoughts & \\
\hline Reassurance seeking & \\
\hline Avoidance & \\
\hline Excessive body checking & \\
\hline Functional impairments & \\
\hline Excessive Distress & \\
\hline Difficulty making plans for the future & \\
\hline $\begin{array}{l}\text { Are there other examples of maladaptive } \\
\text { coping strategies present in clinical FCR } \\
\text { that should be added? (Besides those listed } \\
\text { above) }\end{array}$ & Open Response (maximum 5) \\
\hline $\begin{array}{l}\text { Would you add any other characteristics of } \\
\text { clinical FCR? }\end{array}$ & Open Response (maximum 5) \\
\hline Would you consider "difficulty making & Functional impairment \\
\hline
\end{tabular}



impairment or a standalone defining Standalone defining feature Other - open response

\section{Round 2}

\section{Rating Additional Criteria}

Thank you for participating in Round 1 of the International Delphi on clinical FCR!

Based on Round 1, the following features of clinical FCR reached consensus (i.e., at least 75\% of participants rated the items $8 / 10$ or more)

- High levels of preoccupation

- High levels of worry

In this round, you will be asked to rate the additional characteristics of clinical FCR suggested in Round 1

\section{Please rate how much you think each of the following are a characteristic of clinical FCR:} \begin{tabular}{l|l} 
Uncontrollable worry/fear/anxiety & 10-point visual analogue scale
\end{tabular}

Persistent anxiety/worry/fear (i.e., is not only 0 - "Is not a characteristic of clinical FCR" present when one has an upcoming check-up, $\quad 10$ - "Is a characteristic of clinical FCR" or is waiting for test results)

This worry/anxiety/fear is considered excessive by the individual

This worry/anxiety/fear is considered excessive based on clinician's opinion Hypervigilance or hypersensitivity to bodily sensations or physical symptoms for signs of cancer recurrence

Persistent emotional reaction to the anxiety/worry/fear (i.e., irritability, crying, distress)

Misinterpretation of bodily symptoms as signs of recurrence

High perceived risk of cancer recurrence

The following maladaptive coping strategies were suggested in Round 1.

- Excessive reassurance from a health care professional that the cancer has not returned (requesting a second opinion, additional testing after negative results)

- Excessive information seeking (e.g., excessively conducting internet searches about signs and symptoms of recurrence, prognosis, etc.)

- Substance use to cope with anxiety/worry/fear 
- Excessive lifestyle changes (i.e., excessively exercising, drastic changes in diet)

- Avoidance of check-ups, hospital visits, self-examinations

- Avoidance of reminders (e.g., advertisements, media, other cancer survivors/patients)

- Cognitive avoidance - supressing thoughts, excessive use of distraction

Please rate how much you think the presence of AT LEAST ONE of the

following maladaptive coping strategies would characterize clinical FCR: 10-point visual analogue scale 0 - "Is not a characteristic of clinical FCR" 10 - "Is a characteristic of clinical FCR"

Please rate how much you think EACH ONE of the maladaptive coping strategies is a characteristic of clinical FCR:

Excessive reassurance from a health care professional that the cancer has not returned (requesting a second opinion, additional testing after negative results)

Excessive information seeking (e.g., excessively conducting internet searches about signs and symptoms of recurrence, prognosis, etc.)

Substance use to cope with anxiety/worry/fear Excessive lifestyle changes (i.e., excessively exercising, drastic changes in diet)

Avoidance of check-ups, hospital visits, selfexaminations

Avoidance of reminders (e.g., advertisements, media, other cancer survivors/patients)

Cognitive avoidance - supressing thoughts, excessive use of distraction 10-point visual analogue scale

0 - "Is not a characteristic of clinical FCR"

10 - "Is a characteristic of clinical FCR"

Many examples of impairment in functioning were suggested in Round 1, including:

- Sleep disturbances (i.e., insomnia)

- Relationship difficulties (i.e., avoiding relationships, difficulty with intimacy)

- Difficulties making plans for the future, reduced enjoyment in activities

- Difficulty staying in the present moment

- Difficulties with concentration or attention due to the cancer-related worries/fear

- Difficulties in work roles

Please rate how much you think the presence

of impairment in functioning is a

10-point visual analogue scale characteristic of clinical FCR 0 - "Is not a characteristic of clinical FCR" 10 - "Is a characteristic of clinical FCR" Please rate how much you think EACH ONE of the examples of impairment in functioning is a 


\begin{tabular}{|c|c|}
\hline \multicolumn{2}{|l|}{ characteristic of clinical FCR: } \\
\hline Sleep disturbances (i.e., insomnia) & \multirow{8}{*}{$\begin{array}{l}\text { 10-point visual analogue scale } \\
0 \text { - "Is not a characteristic of clinical FCR" } \\
10 \text { - "Is a characteristic of clinical FCR" }\end{array}$} \\
\hline Relationship difficulties (i.e., avoiding & \\
\hline relationships, difficulty with intimacy) & \\
\hline Difficulties making plans for the future & \\
\hline Reduced enjoyment in activities & \\
\hline Difficulty staying in the present moment & \\
\hline $\begin{array}{l}\text { Difficulties with concentration or attention due } \\
\text { to cancer-related worries }\end{array}$ & \\
\hline Difficulties in work roles & \\
\hline
\end{tabular}

\section{Round 3.}

Thank you for completing Round 2 of the International Delphi Study on Clinical FCR! Items that have reached consensus ( $70 \%$ rated $8 / 10$ or higher) as defining features of clinical FCR:

Round 1

\begin{tabular}{|c|}
\hline Item \\
\hline High levels of preoccupation \\
\hline High levels of worry \\
\hline
\end{tabular}

Round 2

\begin{tabular}{|c|}
\hline Item \\
\hline $\begin{array}{c}\text { Hypervigilance or hypersensitivity to bodily sensations or physical } \\
\text { symptoms for signs of cancer recurrence }\end{array}$ \\
\hline
\end{tabular}

In Round 2, the following items approached consensus (65\%-69\% of participants rated 8/10 or higher) as defining features of clinical FCR:

\begin{tabular}{|c|}
\hline Item \\
\hline The individual reports impairment in functioning \\
\hline Uncontrollable worry/fear/anxiety \\
\hline $\begin{array}{c}\text { Persistent anxiety/worry/fear (i.e., is not only present when one has an } \\
\text { upcoming check-up, or is waiting for test results) }\end{array}$ \\
\hline Presence of AT LEAST ONE maladaptive coping strategy \\
\hline Difficulties making plans for the future \\
\hline
\end{tabular}

There are three parts in the Round 3 of the International Delphi on Clinical FCR.

In Part 1, you will be asked to consider the use of these items to identify individuals as having clinical FCR;

In Part 2, you will be asked to consider the use of these items to diagnose individuals with clinical FCR; and 
In Part 3, you will be asked to consider the applicability of established diagnostic criteria for clinical FCR. (i.e., Health Anxiety in the upcoming ICD-11; and DSM-5 Illness Anxiety Disorder, and Somatic Symptom Disorder).

\section{Part 1: Identifying Individuals with Clinical FCR}

\begin{tabular}{|c|c|}
\hline Question & Response Option \\
\hline \multicolumn{2}{|c|}{ Please indicate your responses to the following questions: } \\
\hline $\begin{array}{l}\text { Do you think it is helpful to identify } \\
\text { individuals with clinical FCR? }\end{array}$ & Yes/No and why? (Open response option) \\
\hline \multicolumn{2}{|c|}{ IF YES } \\
\hline $\begin{array}{l}\text { Which of the characteristics MUST be } \\
\text { present to identify an individual with } \\
\text { clinical FCR? }\end{array}$ & $\begin{array}{l}\text { Check all that apply. (Open response } \\
\text { option for comments) }\end{array}$ \\
\hline $\begin{array}{l}\text { How many of the characteristics MUST be } \\
\text { present for the identification of individuals } \\
\text { with clinical FCR }\end{array}$ & $\begin{array}{l}\text { Check all that apply. (Open response } \\
\text { option for comments) }\end{array}$ \\
\hline $\begin{array}{l}\text { For how long should the defining features } \\
\text { of clinical FCR be present to meet the } \\
\text { definition of clinical FCR? (i.e., all cancer } \\
\text { survivors likely experience these features, } \\
\text { but for how long must they be present in } \\
\text { order to be considered a "clinical" issue?) }\end{array}$ & $\begin{array}{l}\text { Drop down menu with options of Weeks or } \\
\text { Months } \\
\text { Drop down menu with numbers 1-100 } \\
\text { Additional option of "No duration } \\
\text { required" }\end{array}$ \\
\hline $\begin{array}{l}\text { Would you feel comfortable using these } \\
\text { defining features to identify an individual } \\
\text { as having clinical FCR? }\end{array}$ & $\begin{array}{l}\text { Yes/No Please explain (Open response } \\
\text { option) }\end{array}$ \\
\hline
\end{tabular}

Part 2: Diagnosing Individuals with Clinical FCR

Preliminary Question: Does your profession allow you to diagnose? Yes/No

\begin{tabular}{|l|l|}
\hline \multicolumn{1}{|c|}{ Question } & \multicolumn{1}{|c|}{ Response Option } \\
\hline $\begin{array}{l}\text { Do you think it is helpful to diagnose } \\
\text { individuals with clinical FCR? }\end{array}$ & Yes/No and why? (Open response option) \\
\hline \multicolumn{2}{|c|}{ IF YES } \\
\hline $\begin{array}{l}\text { Which of characteristics MUST be present } \\
\text { to diagnose an individual with clinical } \\
\text { FCR? }\end{array}$ & $\begin{array}{l}\text { Check all that apply. (Open response } \\
\text { option for comments) }\end{array}$ \\
\hline $\begin{array}{l}\text { How many of the above characteristics } \\
\text { MUST be present for the diagnosis of } \\
\text { clinical FCR }\end{array}$ & $\begin{array}{l}\text { Check all that apply. (Open response } \\
\text { option for comments) }\end{array}$ \\
\hline $\begin{array}{l}\text { For how long should the defining features } \\
\text { of clinical FCR be present to meet the } \\
\text { diagnosis of clinical FCR? (i.e., all cancer } \\
\text { survivors likely experience these features, } \\
\text { but for how long must they be present in }\end{array}$ & $\begin{array}{l}\text { Drop down menu with options of Weeks or } \\
\text { Months } \\
\text { Drop down menu with numbers 1-100 } \\
\text { required" }\end{array}$ \\
\hline
\end{tabular}


order to be considered a "clinical" issue?) Would you feel comfortable using these defining features to diagnose an individual with clinical FCR?
Yes/No Please explain (Open response option)

\section{Part 3: Applying Established Diagnostic Criteria to Clinical FCR}

An alternative to using these criteria is to use an already established diagnosis:

\section{ICD-11 Health Anxiety/Hypochondriasis}

In preparation for the ICD-11, Stein et al. (2016) have proposed that the essential diagnostic features of Hypochondriasis/Health Anxiety are:

- Persistent preoccupation (e.g., at least one hour a day) or fear about the possibility of having one or more serious, progressive or life-threatening illnesses

- The preoccupation is associated with catastrophic misinterpretations of bodily signs or symptoms, including normal or commonplace sensations (e.g., worrying that a tension headache is indicative of a brain tumour).

- The preoccupation is manifest either in:

○ Repetitive and excessive health-related behaviours, such as repeatedly checking of the body for evidence of illness, spending inordinate amounts of time searching for information about the feared illness, repeatedly seeking reassurance (e.g., arranging multiple medical consultations); or

○ Maladaptive avoidance behaviour related to health (e.g., avoids medical appointments).

- The symptoms result in significant distress or significant impairment in personal, family, social, educational, occupational or other important areas of functioning.

Would you feel comfortable using the diagnostic criteria for ICD-11 Health Anxiety to diagnose an individual with clinical FCR?

\section{Illness Anxiety Disorder}

A Preoccupation with having or acquiring a serious illness.

B Somatic symptoms are not present or, if present, are only mild in intensity. If another medical condition is present or there is a high risk for developing a medical condition (e.g., strong family history is present), the preoccupation is clearly excessive or disproportionate.

$\mathrm{C}$ There is a high level of anxiety about health, and the individual is easily alarmed about personal health status.

D The individual performs excessive health-related behaviors (e.g., repeatedly checks his or her body for signs of illness) or exhibits maladaptive avoidance (e.g., avoids doctor appointments and hospitals).

E Illness preoccupation has been present for at least 6 months, but the specific illness that is feared may change over that period of time. 
F The illness-related preoccupation is not better explained by another mental disorder, such as somatic symptom disorder, panic disorder, generalized anxiety disorder, body dysmorphic disorder, obsessive-compulsive disorder, or delusional disorder, somatic type.

Specify whether:

Care-seeking type: Medical care, including physician visits or undergoing tests and procedures, is frequently used.

Care-avoidant type: Medical care is rarely used.

\begin{tabular}{|l|l}
\hline Would you feel comfortable using the & Yes/No and Why? (Open response option)
\end{tabular} diagnostic criteria for DSM-5 Illness Anxiety Disorder to diagnose an individual with clinical FCR?

\section{Somatic Symptom Disorder}

A One or more somatic symptoms that are distressing or result in significant disruption of daily life.

B Excessive thoughts, feelings, or behaviors related to the somatic symptoms or associated health concerns as manifested by at least one of the following:

Disproportionate and persistent thoughts about the seriousness of one's symptoms.

Persistently high level of anxiety about health or symptoms.

Excessive time and energy devoted to these symptoms or health concerns.

C Although any one somatic symptom may not be continuously present, the state of being symptomatic is persistent (typically more than 6 months).

Specify if:

With predominant pain (previously pain disorder): This specifier is for Specify if:

individuals whose somatic symptoms predominantly involve pain.

Persistent: A persistent course is characterized by severe symptoms, marked impairment, and long duration (more than 6 months). Specify current severity:

Mild: Only one of the symptoms specified in Criterion B is fulfilled. fulfilled.

Moderate: Two or more of the symptoms specified in Criterion B are

Severe: Two or more of the symptoms specified in Criterion B are fulfilled, plus there are multiple somatic complaints (or one very severe somatic symptom).

\begin{tabular}{l|l} 
Would you feel comfortable using the & Yes/No and Why? (Open response option) \\
diagnostic criteria for DSM-5 Somatic & \\
Symptom Disorder to diagnose an & \\
individual with clinical FCR? & \\
\hline
\end{tabular}


Table 1. Round 1 results

\section{Supplementary File 2} Summary of Delphi Rounds

\begin{tabular}{|c|c|c|c|}
\hline Item & Mean & $8 / 10$ or higher $(\%)$ & Range \\
\hline High levels of preoccupation & 7.91 & $48 / 64=75 \%$ & $2-10$ \\
\hline High levels of worry & 8.50 & $52 / 65=80 \%$ & $2-10$ \\
\hline High levels of rumination & 7.74 & $43 / 65=66 \%$ & $0-10$ \\
\hline High levels of intrusive thoughts & 7.66 & $35 / 65=54 \%$ & $3-10$ \\
\hline Reassurance seeking & 7.17 & $32 / 65=49 \%$ & $1-10$ \\
\hline Avoidance & 6.31 & $20 / 62=32 \%$ & $2-10$ \\
\hline Excessive body checking & 7.05 & $31 / 64=48 \%$ & $1-10$ \\
\hline Functional impairments & 6.18 & $18 / 62=29 \%$ & $1-10$ \\
\hline Excessive Distress & 7.69 & $41 / 65=63 \%$ & $1-10$ \\
\hline $\begin{array}{l}\text { Difficulty making plans for the } \\
\text { future }\end{array}$ & 6.86 & $30 / 65=46 \%$ & $1-10$ \\
\hline $\begin{array}{l}\text { Would you consider "difficulty } \\
\text { making plans for the future" an } \\
\text { aspect of functional impairment or a } \\
\text { standalone defining feature? }\end{array}$ & \multicolumn{3}{|c|}{$\begin{array}{l}\text { Functional Impairment: } 28 / 65=43 \% \\
\text { Standalone: } 33 / 65=51 \% \\
\text { Other: } 4 / 65=6 \%\end{array}$} \\
\hline
\end{tabular}

Table 2. Round 2 results

\begin{tabular}{|c|c|c|c|}
\hline Item & Mean & $8 / 10$ or higher $(\%)$ & Range \\
\hline Uncontrollable worry/fear/anxiety & 7.56 & $28 / 43=65 \%$ & $2-10$ \\
\hline Persistent anxiety/worry/fear & 7.30 & $29 / 43=67 \%$ & $1-10$ \\
\hline $\begin{array}{l}\text { This worry/anxiety/fear is considered excessive by the } \\
\text { individual }\end{array}$ & 6.40 & $16 / 43=37 \%$ & $0-10$ \\
\hline $\begin{array}{l}\text { This worry/anxiety/fear is considered excessive based } \\
\text { on clinician's opinion }\end{array}$ & 6.62 & $17 / 42=40 \%$ & $0-10$ \\
\hline $\begin{array}{l}\text { Hypervigilance or hypersensitivity to bodily sensations } \\
\text { or physical symptoms for signs of cancer recurrence }\end{array}$ & 8.05 & $30 / 43=70 \%$ & $4-10$ \\
\hline $\begin{array}{l}\text { Persistent emotional reaction to the anxiety/worry/fear } \\
\text { (i.e., irritability, crying, distress) }\end{array}$ & 6.35 & $16 / 43=37 \%$ & $0-10$ \\
\hline $\begin{array}{l}\text { Misinterpretation of bodily symptoms as signs of } \\
\text { recurrence }\end{array}$ & 7.30 & $20 / 43=47 \%$ & $0-10$ \\
\hline High perceived risk of cancer recurrence & 6.70 & $19 / 43=44 \%$ & $0-10$ \\
\hline \multicolumn{4}{|l|}{ Maladaptive Coping } \\
\hline $\begin{array}{l}\text { Presence of AT LEAST ONE of the following } \\
\text { maladaptive coping strategies }\end{array}$ & 7.78 & $24 / 37=65 \%$ & $3-10$ \\
\hline $\begin{array}{l}\text { Excessive reassurance from a health care professional } \\
\text { that the cancer has not returned }\end{array}$ & 6.90 & $20 / 41=49 \%$ & $0-10$ \\
\hline $\begin{array}{l}\text { Excessive information seeking (e.g., excessively } \\
\text { conducting internet searches about signs and symptoms } \\
\text { of recurrence, prognosis, etc.) }\end{array}$ & 7.07 & $21 / 41=51 \%$ & $3-10$ \\
\hline Substance use to cope with anxiety/worry/fear & 5.02 & $7 / 41=17 \%$ & $0-9$ \\
\hline $\begin{array}{l}\text { Excessive lifestyle changes (i.e., excessively exercising, } \\
\text { drastic changes in diet) }\end{array}$ & 5.80 & $11 / 41=27 \%$ & $0-8$ \\
\hline
\end{tabular}




\begin{tabular}{llll}
\hline $\begin{array}{l}\text { Avoidance of check-ups, hospital visits, self- } \\
\text { examinations }\end{array}$ & 6.20 & $15 / 41=37 \%$ & $1-10$ \\
\hline $\begin{array}{l}\text { Avoidance of reminders (e.g., advertisements, media, } \\
\text { other cancer survivors/patients) }\end{array}$ & 6.51 & $17 / 41=41 \%$ & $2-10$ \\
\hline $\begin{array}{l}\text { Cognitive avoidance (e.g., supressing thoughts, } \\
\text { excessive use of distraction) }\end{array}$ & 6.76 & $21 / 41=51 \%$ & $1-10$ \\
\hline \multicolumn{4}{c}{ Impairment in Functioning } \\
\hline $\begin{array}{l}\text { The individual reports impairment in functioning } \\
\text { Sleep disturbances (i.e., insomnia) }\end{array}$ & 6.85 & $27 / 40=67.5 \%$ & $3-10$ \\
\hline $\begin{array}{l}\text { Relationship difficulties (i.e., avoiding relationships, } \\
\text { difficulty with intimacy) }\end{array}$ & 5.56 & $7 / 41=17 \%$ & $0-10$ \\
\hline $\begin{array}{l}\text { Difficulties making plans for the future } \\
\text { Reduced enjoyment in activities }\end{array}$ & 7.63 & $27 / 41=66 \%$ & $3-10$ \\
\hline $\begin{array}{l}\text { Difficulty staying in the present moment } \\
\text { Difficulties with concentration or attention due to } \\
\text { cancer-related worries }\end{array}$ & 6.85 & $16 / 41=39 \%$ & $2-10$ \\
\hline \begin{tabular}{l} 
Difficulties in work roles \\
\hline
\end{tabular} & 5.95 & $6 / 41=15 \%$ & $1-10$ \\
\hline
\end{tabular}

Table 3. Round 3 characteristics to identify clinical FCR

\begin{tabular}{ll}
\hline Item & \% of participants selected as "must be present" \\
\hline Uncontrollable worry/fear/anxiety & $27 / 45=60 \%$ \\
Persistent worry/fear/anxiety & $37 / 45=82 \%$ \\
At least one maladaptive coping & $25 / 45=56 \%$ \\
Difficulties making plans for the future & $12 / 45=27 \%$ \\
Hypervigilance or hypersensitivity to bodily & $33 / 45=73 \%$ \\
sensations or physical symptoms for signs & \\
of cancer recurrence & \\
Impairment in functioning & $29 / 45=64 \%$ \\
High levels of preoccupation & $26 / 45=55 \%$ \\
High levels of worry & $24 / 45=53 \%$ \\
\hline
\end{tabular}

*Note: sum out of 45 because 3 participants only completed first question "Do you think it is helpful to identify individuals with clinical FCR?"

Table 4. Round 3 characteristics to diagnose clinical FCR

\begin{tabular}{ll}
\hline Item & \% of participants selected as "must be present" \\
\hline Uncontrollable worry/fear/anxiety & $18 / 32=56 \%$ \\
Persistent worry/fear/anxiety & $24 / 32=75 \%$ \\
At least one maladaptive coping & $18 / 32=56 \%$ \\
Difficulties making plans for the future & $7 / 32=22 \%$ \\
Hypervigilance or hypersensitivity to bodily & $20 / 32=63 \%$ \\
sensations or physical symptoms for signs & \\
of cancer recurrence & \\
Impairment in functioning & $17 / 32=53 \%$ \\
High levels of preoccupation & $15 / 32=47 \%$ \\
High levels of worry & $16 / 32=50 \%$ \\
\hline
\end{tabular}

